\title{
O POEMA “TRAGÉDIA BRASILEIRA”, DE MANUEL BANDEIRA, SOB A ÓTICA DA SEMIOLINGUÍSTICA
}

\section{THE “BRAZILIAN TRAGEDY” POEM BY MANUEL BANDEIRA, UNDER THE SEMIOLINGUISTIC OPTICS}

Cristiani Dalia de Mello ${ }^{1}$

RESUMO: Este artigo tem como objetivo principal estudar com mais propriedade o entrelaçamento entre as teorias da análise do discurso, nas concepções de Charaudeau, e a literatura. Para isso, recorreu-se aos estudos de Ida Lúcia Machado (1999, 2001,2002), para se analisar o poema "Tragédia Brasileira" sob a ótica da Semiolinguística.

Palavras-chave: Poema, Semiolinguística, Análise do Discurso.

\begin{abstract}
This article has as its main objective to studywill be carried out ofthe appropriateness of the interrelationships between theories, in the conceptions of Charaudeau, and literature. The theoretical studies of Ida Lúcia Machado (1999, 2001, 2002) will lead us to analysis of the poem "Brasilian Tragedy" as seen through Semiolinguistics.
\end{abstract}

Palabras claves: Poem, Semiolinguistics, Discourse Analysis. 


\section{INTRODUÇÃO}

A partir das teorias que dizem respeito à Análise do Discurso, na concepção de Charaudeau, fez-se mister um exame mais detalhado sobre o amalgamento da Semiolinguística com a Literatura. Para isso, este artigo fará uso apenas dos textos de Machado1, nos quais a autora discute justamente a inclusão da Análise do Discurso na Literatura tendo em vista o gênero "paródia". Por este motivo, alguns conceitos abordados pela autora serão apropriados neste texto para a análise de um texto poético, escrito em prosa, a saber, o poema “Tragédia Brasileira”, de Manuel Bandeira.

Segundo Machado (1999), a paródia possui conceitos polissêmicos, dentre os quais, diante do aspecto abordado neste artigo, seria o que se refere à re-apresentação polêmica de uma nova linguagem dentro de um determinado discurso-alvo.

Tomando as concepções de Charaudeau (2001), na paródia, o sujeito-comunicante invoca um sujeito-enunciador, atribuindo ao texto produzido a sua visão estereotipada do mundo real ao imaginário, "brincando" com as situações comuns do dia-a-dia, para levar o leitor a um final inesperado com uma certa dose de ironia. Isso pode ser observado nas diversas ações linguajeiras, principalmente quando a referência são temas em evidência, como os discursos institucionalizados pela classe dominante, ou seja, as questões políticas, religiosas, as de gênero, enfim, os discursos sociais.Portanto, se para Charaudeau existe um contrato social entre o eu-comunicante e o tu-interpretante em um mundo psico-sócio-cultural, aquele sujeito deve ter um espírito crítico, ou melhor, motivar o sujeito-destinatário a ser o tu- interpretante, capacitando-o a enxergar os dogmas e as ideias feitas como algo a ser contestado.

Daí a importância da paródia, pois a polifonia de vozes $^{3}$ existentes neste gênero cria uma interrogação aos ditos já cristalizados. Faz-se mister ressaltar também que existe uma intencionalidade deste eureal (eu-comunicante) em influenciar o tureal (tu-interpretante), porém esse desejo só se poderá realizar em contextos partilhados por um e outro, ou melhor, a existência de uma conformidade a certas condições discursivas.

\begin{abstract}
Aliás, a análise é mais conflituosa ainda, pois Charaudeau coloca o ato de linguagem como uma aventura:

Se o sujeito-comunicante pode ter o domínio da configuração do seu projeto

de comunicação, ele não tem controle nem sobre o que pode deixar transparecer do seu inconsciente nem sobre os efeitos que seu projeto poderá efetivamente ter junto ao(s) sujeito(s) interpretante(s). $\mathrm{O}$ sujeitocomunicante realiza uma "aposta": a de que os seus procedimentos discursivos produzirão os efeitos desejados junto ao sujeitointerpretante.(DIAS, 2001, p. 33 )
\end{abstract}

No caso específico da análise aqui proposta, Manuel Bandeira é um EU que possui o estatuto de poeta e de escritor. No texto analisado, posteriormente, ele adota o contrato de "poeta-jornalista", entretanto, o seu EU-enunciador relata o estilo próprio dele, cansado da eloquência parnasiana, do rebuscamento da língua, dos barbarismos, dos puristas, conforme é aludido, efusivamente, em um de seus poemas "Poética". Assim, esse EU-enunciador evoca um TU-interpretante (leitor real), tentando seduzir o TU-destinatário (leitor virtual), com uma linguagem direta, simples, instintiva e inata.

2 Professora da Pós-Graduação em Estudos Linguísticos, na Faculdade de Letras da UFMG, coordenadora do NAD (Núcleo de Análise do Discurso).

3 A polifonia de vozes foi introduzida por Bakhtin, nos seus trabalhos sobre a literatura, para caracterizar as obras, por exemplo os romances de Dostoievski (Bakhtin, 1970), em que várias “vozes” se exprimem sem que nenhuma seja dominante.Mas ela foi explorada pelos linguistas, em particular Ducrot, para levar em conta os múltiplos casos em que aquele que produz materialmente o enunciado não se encarrega dele, não se apresenta como seu responsável. v.MAINGUENEAU, D. Termos-chave da análise do discurso. UFMG, 2000. 
Voltando aos conceitos que serão pertinentes à análise escolhida, retoma-se aqui o texto de Ida (2002), no qual ela apresenta a inserção do gênero fait divers, publicado pelas mídias escritas, a outros gêneros, como o literário.

Segundo a autora, fait divers é um estilo narrativo que tem por objetivo informar o público-leitor sobre um determinado acontecimento. Entretanto, o racounter tenta fazer isso a seu modo, ou melhor, inventando um contexto, um pano de fundo para a informação a ser veiculada. Retrata-se, assim, um jogo de efeitos reais e ficcionais. Como exemplo, relembraria a atuação do repórter Gil Gomes, apresentador de histórias reais trágicas, numa emissora de TV, com uma pitada de musicalidade e suspense.

Para Machado, a palavra tenta produzir efeitos de realidade, e.g., outros sujeitos passam a fazer parte da narrativa, ou quando há descrições dos próprios actantes da história - nomes, descrição física -, ou datas, nomes de ruas ou de cidades, números de casa. narrados correspondem a um dizer-real para um dizer-ficção, incluindo o extraordinário, a novidade, o absurdo, que emocionam o ser humano, pois o envolvem numa atmosfera de valores abstratos como o amor, ciúme, piedade, ódio, sacrifício.

Como a própria autora relata no trecho destacado abaixo, ao inserir a Semiolinguística para a explicação desse gênero mencionado:

\footnotetext{
... o sujeito-comunicante, para colocar em palavras um acontecimento social deste tipo, precisa conceber um "projeto de palavra" onde certas estratégias linguageiras serão necessárias para que o documento escrito atinja o leitor, de alguma forma. O sujeitocomunicante em questão "aciona" um sujeito-enunciador que vai desenvolver, no
} mesmo dados geográficos verificáveis -

Nessa perspectiva sedutora, os fatos

espaço das palavras, tais estratégias. Elas têm uma dupla finalidade:

(i) dar uma credibilidade maior à instância produtora de informação;

(ii) dotar esta informação de um certo poder de sedução. (MACHADO, 2002, p.67)

A partir desse pequeno esboço sobre a teoria de Charaudeau, do conceito de paródia e do fait divers, pode-se analisar o "poemaprosa” Tragédia Brasileira, de Manuel Bandeira, descrito abaixo:

\section{TRAGÉDIA BRASILEIRA}

Misael, funcionário da Fazenda, com 63 anos de idade.

Conheceu Maria Elvira na Lapa prostituída, com sífilis, dermite nos dedos, uma aliança empenhada e os dentes em petição de miséria. Misael tirou Maria Elvira da vida, instalou-a num sobrado no Estácio, pagou médico, dentista, manicura...Dava tudo quanto ela queria.

Quando Maria Elvira se apanhou de boca bonita, arranjou logo um namorado. Misael não queria escândalo. Podia dar uma surra, um tiro, uma facada.Não fez nada disso: mudou de casa.Viveram três anos assim. Toda vez que Maria Elvira arranjava namorado, Misael mudava de casa.

Os amantes moraram no Estácio, Rocha, Catete, Rua General Pedra, Olaria, Ramos, Bonsucesso, Vila Isabel, Rua Marquês de Sapucaí, Niterói, Encantado, Rua Clapp, outra vez no Estácio, Todos os Santos, Catumbi, Lavradio, Boca do Mato, Inválidos... Por fim na Rua da Constituição, onde Misael, privado de sentidos e de inteligência, matou-a com seis tiros, e a polícia foi encontrá-la caída em decúbito dorsal, vestida de organdi azul. ${ }^{4}$

Manuel Bandeira representou, desde o primeiro momento, a reação da poesia. Da poesia compreendida como uma relação das coisas com um "eu”, ou melhor, como a relação de um sujeito com um objeto. Como disse Jean Florence:

Le beau est me sorte de vrai physique; le
poétique n'est jamais qu'une suite du vrai
moral. La vie est une poésie parfaite. Mais la
parfaite beauté n'est pas vivante et c'est peut-
être la mort. La poésie, c'est de la beauté qui
n'est pas encore; la beauté c'est de la poésie
qui n'est plus.
La poésie est dan le repport des choses; a
moi, dans mon rapport aux choses; la beauté
est dans le rapport des choses entre elles ou

4 Disponível em < http://www.algumapoesia.com.br/poesia2/poesianet239.htm> Acesso em 12/09/2019. 
des parties d'une même chose les unes aux autres (FLORENCE, 1978, p.110).

A poesia de Manuel Bandeira não se tratava, é claro, de um fato novo, de uma descoberta. Era simplesmente a volta à verdadeira e natural posição do peta, cujo abandono, exatamente, consistira o pecado capital contra a poesia. Um arranjo de versos e de imagens sem compromisso e sem limites, relatando o familiar e o cotidiano, o insatisfeito e o libertino, o popular e o realista. São essas várias "vozes” de Manuel Bandeira que o faziam ao mesmo tempo agente e paciente, sofrendo primeiro a poesia que produzia, toda feita da vida que dos seus lábios corria deixando um acre sabor na boca.

E é nessa orquestra polifônica, trazendo o dialogismo ${ }^{5}$, a interação, a intertextualidade que Tragédia Brasileira se desenvolve, podendo unir a paródia ao gênero lírico, a partir de um fait divers.

Numa análise traçada na linha da Semiolinguística e sob a visão de fait divers, ressalta-se que Tragédia Brasileira foi escrito para um artigo de jornal e, neste, o Eu-poeta-jornalista Manuel Bandeira transformou-se no seu Eu-enunciador irreverente e irônico.

Em questões linguísticas, o texto inicia-se com a apresentação dos actantes: Misael e Maria Elvira, com suas respectivas identificações: (i) Misael, funcionário da Fazenda, 63 anos de idade; (ii) Maria Elvira, prostituída, com sífilis, dermite nos dedos, endividada, mora no subúrbio do Rio de Janeiro, e os dentes em petição de miséria. Ressaltam-se, nesse começo, indícios para um provável desequilíbrio narrativo, pelas condições sociais diferenciadas de Misael e Maria Elvira, mas ao mesmo tempo colocam-nos numa posição de igualdade, pois um era velho, hipoteticamente desprezado pelas mulheres e a outra, prostituída, desprezada pela sociedade. Apesar de a atividade profissional de |Misael querer mostrar uma situação financeira razoável, ele transforma Maria Elvira em uma mulher "honrada".

Nessa visão realista, podemos identificar alguns lugares-comuns- topoï, marcados por expressões linguísticas de uso coloquial : “...tirou Maria Elvira da vida” ; “... pagou médico, dentista, manicura...” Ao mesmo tempo, podemos pressupor a diferença de idade entre os actantes, por serem relatados os sessenta e três anos de Misael, como um silogismo do senso-comum, no qual "todo homem idoso quer reafirmar a sua virilidade”, ora, Misael era idoso, daí procurar uma mulher "nova", supostamente bonita “... se apanha de boca bonita”, para confirmar o discurso machista da sociedade.

Entretanto, há uma quebra do relaxamento inicial, quando Maria Elvira arranja um "namorado". Porém, antes mesmo que isso se torne um conflito, Misael deixa seus valores morais e se muda de casa. Nesse instante, a ação inesperada do actante atua como uma provocação ao interlocutor, o qual supunha uma reação mais contundente por parte de Misael.

Traição sugere "surra, tiro, facada": ações clássicas, no âmbito passional. Essa passagem é altamente marcada pela presença do outro no inconsciente de Misael, o que se pode observar pelo demarcador temporal nos próprios verbos, que antes relatavam o caso no pretérito perfeito para agora serem escritos no tempo do imaginário, da fantasia, o pretérito imperfeito. "Misael não queria escândalo. Podia dar uma surra, um tiro, uma facada."

Aproveitando-se da Semiolinguística, pode-se perceber no enunciado anterior, a voz do Tu-destinatário amalgamado com o Eu-enunciador. É como se abrissem aspas

5 Dialogismo bakhtiniano: a paródia seria um desses gêneros que colocam em situação de diálogo dois discursos diferentes, comportando sempre um déjà-dit, c. Ida L. Machado. 
para um momento de "poderia ter feito", mas não fez. Assim, volta-se ao tempo verbal inicial, tentando manter-se a estabilidade do início. Misael, simplesmente, mudou de casa.

Mais uma vez, a ironia toma conta do texto, pois o actante Misael viveu três anos mudando de casa e, ao mesmo tempo, o relato assume as características de fait divers expondo detalhadamente todos os bairros do subúrbio do Rio de Janeiro, como se fosse um artigo de jornal (como o jornal Notícias Populares) sobre um caso passional.

Enfim, interrompem-se os lugares, fixando-se em apenas um: Rua da Constituição, onde o querer-fazer de Misael priva-se "de sentidos e inteligência", assumindo um dever-fazer, que se transforma no poder-fazer, legitimado por um ideal de justiça ( o que pode ser confirmado até pelo nome da Rua: Constituição = lei). Misael assume a função de destinador-julgador e avalia os percursos narrativos pregressos, passando a considerar Maria Elvira como um anti-sujeito. E, novamente, o verbo encarnase no pretérito perfeito, finalizando a tragédia que já era esperada: a morte de Maria Elvira, assassinada por Misael, com seis tiros.

Nesse final de texto, observa-se nitidamente a intertextualidade, marcada pela polifonia dos discursos ocorridos em delegacias, cujos valores, na sociedade, apresentam-se de forma séria, mas que são ironizados pelo autor, principalmente, quando estigmatizados como um relato de uma ocorrência policial “...caída em decúbito dorsal, vestida de organdi azul”.

Essa amostra teve como finalidade apenas insuflar uma discussão da Análise do Discurso com a Literatura, para que esta também possa ser inserida naquela, como uma forma de comunicação entre pares, envolvendo qualquer gênero discursivo num contrato de linguagem.

\section{REFERÊNCIAS:}

DIAS, Dylia L. Dimensões da análise do discurso. In: Athos \& Ethos. Vol.1, 2001.

FLORENCE, J. Discours psychanalytique et

discours juridique: remarques sur l'interprétation, dans Michel van de KERCHOVE (dir.), L'interprétation em droit, approche multidisciplinaire. Bruxelles: Éditions des Facultés universitaires Saint-Louis, 1978.

MACHADO, I.L. et alii. Análise do discurso: fundamentos e práticas. Belo Horizonte: FALE/UFMG, 2001. . Ensaios em análise do

discurso. Belo Horizonte: FALE/UFMG, 2002. Fundamentos e dimensões

da análise do discurso. Belo Horizonte: FALE/UFMG, 1999.

MAIGUENEAU, D. Termos-chave da análise do discurso. Belo Horizonte: UFMG, 2000.

Disponível em <

http://www.algumapoesia.com.br/poesia2/poesia net239.htm> Acesso em 12/09/2019 